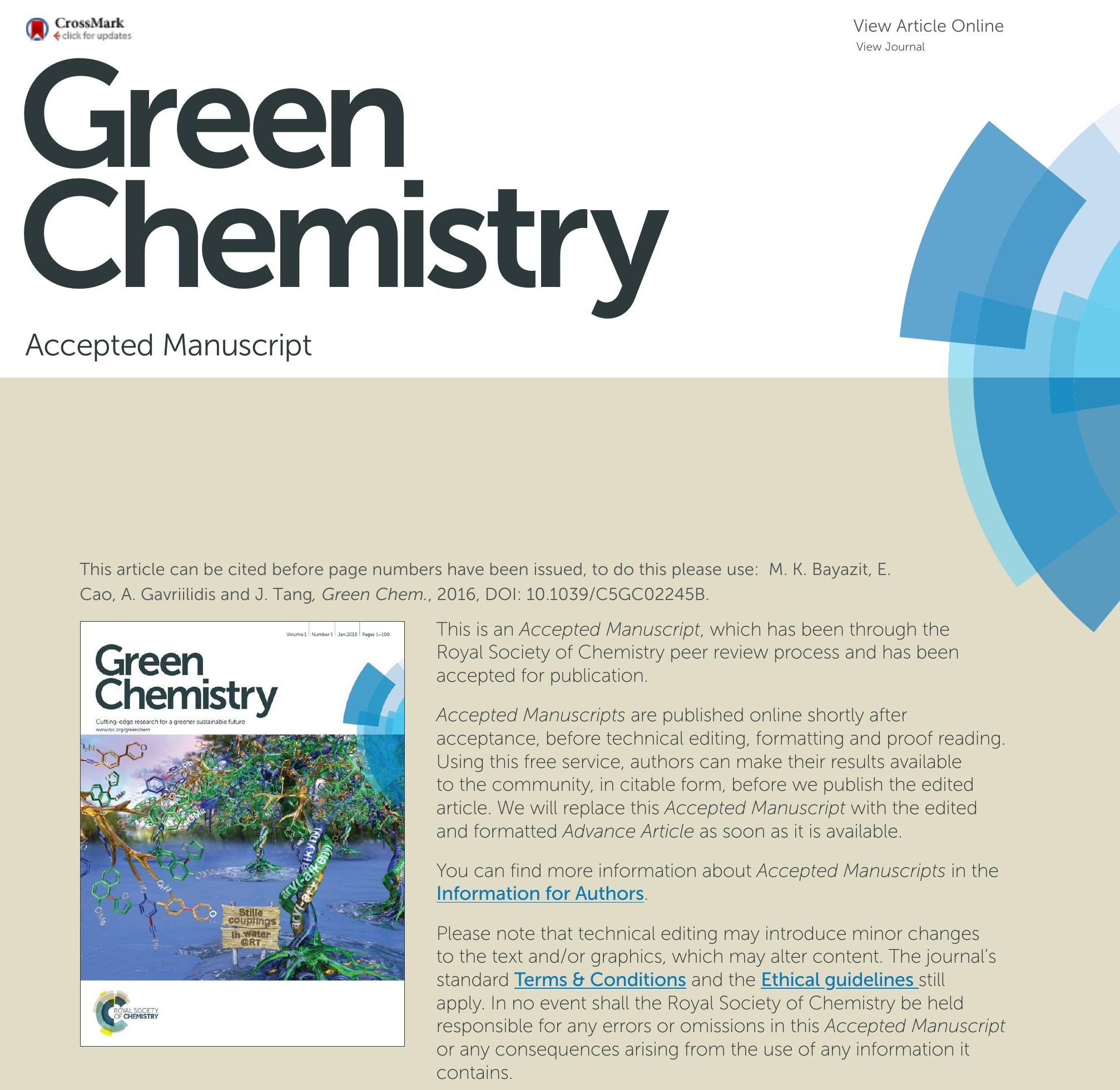

This article can be cited before page numbers have been issued, to do this please use: M. K. Bayazit, E. Cao, A. Gavriilidis and J. Tang, Green Chem., 2016, DOI: 10.1039/C5GC02245B.

This is an Accepted Manuscript, which has been through the Royal Society of Chemistry peer review process and has been accepted for publication.

Accepted Manuscripts are published online shortly after acceptance, before technical editing, formatting and proof reading. sing this free service, authors can make their results available

You can find more information about Accepted Manuscripts in the

Please note that technical editing may introduce minor changes to the text and/or graphics, which may alter content. The journal's standard Terms \& Conditions and the Ethical guidelines still apply. In no event shall the Royal Society of Chemistry be held responsible for any errors or omissions in this Accepted Manuscript contains. 


\title{
Microwave Promoted Continuous Flow Approach to Self-assembled Hierarchical Hematite Superstructures
}

\author{
M. K. Bayazit, E. Cao, A. Gavriilidis and J. Tang* \\ Department of Chemical Engineering, University College London, Torrington Place, London, \\ WC1E 7JE, UK
}

\begin{abstract}
In this work a microwave promoted flow (MWPF) system to reproducibly synthesize selfassembled hierarchical hematite superstructures (Hem-SSs) using sole precursor $\left(\mathrm{Fe}\left(\mathrm{NO}_{3}\right)_{3} .9 \mathrm{H}_{2} \mathrm{O}\right)$ and single mode microwave in aqueous conditions has been developed. The functional characterisation by XRD, (HR)TEM, XPS, UV-vis and Raman spectroscopies proved that highly crystalline ellipsoid Hem-SSs $(\sim 180 \mathrm{~nm} \times 140 \mathrm{~nm})$ were produced, built from primary hematite nanoparticles, 5-10 $\mathrm{nm}$ in size using $0.05 \mathrm{~mol} \mathrm{~L}^{-1}$ precursor concentration, $1 \mathrm{~mL} \mathrm{~min}^{-1}$ flow rate and short reaction time (about $6 \mathrm{~min}$ ). Particles produced via conventional heating $(\mathrm{CH})$ at 120 and $140{ }^{\circ} \mathrm{C}$ in the same flow reactor under similar experimental conditions were found to consist of mixtures of goethite and hematite. The effects of precursor concentration $\left(0.1\right.$ and $\left.0.2 \mathrm{~mol} \mathrm{~L}^{-1}\right)$ and flow rate $\left(2\right.$ and $\left.5 \mathrm{~mL} \mathrm{~min}^{-1}\right)$ on Hem-SSs were further investigated and the synthesis mechanism was also discussed. This novel method opens a window for continuous fabrication of metal or metal oxide nanoparticles/superstructures by a green approach to meet industrial requirement.
\end{abstract}


1

2 Highly-ordered superstructures, so-called mesocrystals, formed via hierarchical self-assembly

3 of primary nanoparticles (NPs) following a non-classical crystallization route are interesting

4 materials due to their distinctive properties including enhanced surface area, accessible pores

5 and tunable electronic, optical and magnetic properties that make them potentially applicable

6 in catalysis, paints, sensors and electronics. ${ }^{1-4}$ Metal oxide superstructures have recently been

7 reviewed, with particular attention on their use for energy conversion and storage

8 applications. ${ }^{5}$ Among them, highly oriented hematite superstructures (Hem-SSs) have

9 attracted specific attention due to their excellent lithium insertion, ${ }^{6,7}$ photocatalytic

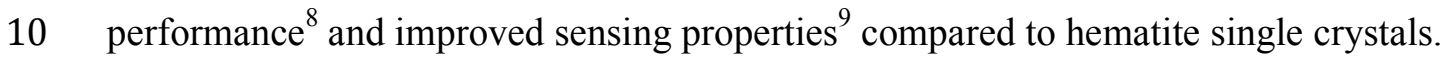

11 Platelike $\alpha-\mathrm{Fe}_{2} \mathrm{O}_{3}$ mesocrystals were used as a support to prepare gold loaded platelike $\alpha$ -

$12 \mathrm{Fe}_{2} \mathrm{O}_{3}$ mesocrystals that were shown to be highly efficient and stable catalyst for $\mathrm{CO}$

13 conversion compared to commercially available $\alpha-\mathrm{Fe}_{2} \mathrm{O}_{3}$ sample (Fluka). ${ }^{9}$ Higher activity

14 was attributed to the significant increase in the (110) diffraction intensity for the platelike $\alpha$ -

$15 \mathrm{Fe}_{2} \mathrm{O}_{3}$ mesocrystal support. ${ }^{9}$ Furthermore, high temperature $\left(400{ }^{\circ} \mathrm{C}\right)$ annealed platelike $\alpha$ -

$16 \mathrm{Fe}_{2} \mathrm{O}_{3}$ mesocrystals showed enhanced gas-sensing sensitivity compared to commercial $\alpha$ -

$17 \mathrm{Fe}_{2} \mathrm{O}_{3}$, probably due to highly-oriented and crystalline $\alpha-\mathrm{Fe}_{2} \mathrm{O}_{3}$ superstructures. ${ }^{9}$ Similarly,

18 as-prepared rhombic $\alpha-\mathrm{Fe}_{2} \mathrm{O}_{3}$ mesocrystals were tested for lithium storage capacity that

19 demonstrated improved cycling stability for 5-50 cycles with storage capacity of $756 \mathrm{~mA} \mathrm{~h} \mathrm{~g}^{-}$

$20{ }^{1}$ after 50 cycles, probably due to the closed and intracrystalline porosity, compared to single-

21 crystal $\alpha-\mathrm{Fe}_{2} \mathrm{O}_{3}$ that showed gradual loss of capacity after $\sim 20$ cycles. $^{6}$

22 Hematite is an n-type semiconductor $\left(\mathrm{E}_{\mathrm{g}}=2.1 \mathrm{eV}\right)$ with rhombohedral crystal structure and is

23 weakly ferromagnetic at room temperature. ${ }^{10}$ Hematite $\left(\alpha-\mathrm{Fe}_{2} \mathrm{O}_{3}\right)$ as a precursor can also be

24 converted into other useful forms of iron oxide such as maghemite $\left(\gamma-\mathrm{Fe}_{2} \mathrm{O}_{3}\right)$ and magnetite

$25\left(\mathrm{Fe}_{3} \mathrm{O}_{4}\right){ }^{11}$ Hematite nanoparticles (Hem-NPs) can be synthesized conventionally by several 
1 techniques including hydrothermal/solvothermal, ${ }^{12,13}$ sol-gel processing ${ }^{14}$ and chemical vapor

2 deposition methods, ${ }^{15}$ using predominately a batch reactor or a large tubular reactor.

3 Alternatively, a microwave-assisted hydrothermal batch reactor can be employed to prepare

4 nanosized hematite particles as catalysts and adsorbents using both $\mathrm{Fe}\left(\mathrm{NO}_{3}\right)_{3}\left(0.1 \mathrm{~mol} \mathrm{~L}^{-1}\right)$

5 and urea $\left(0.5 \mathrm{~mol} \mathrm{~L}^{-1}\right)$ as precursors. ${ }^{16}$

6 Mesocrystals or superstructures of hematite can be prepared by a complicated self-assembly

7 of primary hematite nanoparticles. In these processes, organic surfactants or templates are

8 crucial to form surface stabilized primary Hem-NPs that prevent particle-particle fusion

9 during mesocrystal formation. However, these additives are likely to decompose into

10 hazardous materials at high reaction temperatures and long reaction times.

11 For example, porous plate-like hematite mesocrystals with a dimension of 100-400 nm were

12 synthesized by self-assembly of in-situ prepared Hem-NPs $(5-15 \mathrm{~nm})$ in an ionic liquid

$13[\mathrm{Bmim}] \mathrm{Cl}$, acting as both solvent and templating agent, via a controlled solvent evaporation

14 process reacting $\mathrm{FeCl}_{3} \cdot 6 \mathrm{H}_{2} \mathrm{O}$, water and $n$-butylamine in air at $120^{\circ} \mathrm{C}$ for $20 \mathrm{~h} .{ }^{9}$ Similarly,

15 olive-like photocatalytically active Hem-SSs with size $620 \mathrm{~nm} \times 940 \mathrm{~nm}$ have recently been

16 prepared via self-assembly of primary hematite nanoparticles $(5-10 \mathrm{~nm})$ using $\mathrm{FeCl}_{3}$ and silk

17 fibroin as a biotemplate in water by heating at $160{ }^{\circ} \mathrm{C}$ for $10 \mathrm{~h} .{ }^{8} \mathrm{~A}$ solvothermal approach

18 was used to prepare high-stability hematite mesocrystals from $\mathrm{Fe}\left(\mathrm{NO}_{3}\right)_{3} \cdot 6 \mathrm{H}_{2} \mathrm{O}$ in $N, N$ -

19 dimethylformamide (DMF) and methanol $(\mathrm{MeOH})$ mixture with varying amounts at $180{ }^{\circ} \mathrm{C}$

20 for $24 \mathrm{~h}^{6}{ }^{6}$ It was proposed that the intermediate $\mathrm{NH}_{2}\left(\mathrm{CH}_{3}\right)_{2}{ }^{+}$acted as stabilizer for primary

21 hematite particles and higher amount of methanol conditions produced rhombic

22 (DMF:MeOH; 20:5, v/v) or ellipsoidal (DMF:MeOH; 17:8, v/v) mesocrystals. A

23 hydrothermal method at $200{ }^{\circ} \mathrm{C}$ for $12 \mathrm{~h}$ in ethanol/water mixture $(9: 1, \mathrm{v} / \mathrm{v})$ to synthesize

24 elliptic single-crystalline hematite superstructures was also reported. ${ }^{7}$ 
1 Although the abovementioned methods had their own advantages (e.g. controlling shape and

2 growth direction of superstructures etc.) they obviously required additional chemicals (e.g.

3 reducing agents, surfactants, templates or stabilizers). Furthermore, it is challenging to scale

4 those processes up while retaining the same structure/properties due to long reaction times,

5 limited reactor capacity, high-energy consumption and low product yields. To meet the

6 increasing demand in highly stable, self-assembled, hierarchical superstructures with defined

7 shapes for diverse applications, a green, reproducible and energy/cost efficient technique is

8 desirable, which is also scalable. For this purpose, microwave heating (MH) coupled with

9 continuous flow synthesis may offer an attractive route for the rapid, continuous and

10 controlled growth of self-assembled stable metal oxide superstructures. The use of continuous

11 micro/milliflow technology has gained significant attention in recent years owing to large

12 surface-to-volume ratio that depresses the diffusion times of chemical species. ${ }^{17-21}$

13 Microfluidic systems have been successfully utilized with $\mathrm{CH}$ to carry out chemical reactions

14 and nanocrystal preparation due to their versatility to perform rapid mixing, controllable mass

15 and heat transfer under continuous flow conditions. ${ }^{17}$ Local variations in reaction conditions

16 such as concentration, temperature and reaction time are likely to have significant effect on

17 both nucleation and particle growth, and a better control over these variables may improve

18 the monodispersity, particle size and its distribution, shape and morphology, crystallinity and

19 purity of nano-particles manufactured, which $\mathrm{MH}$ could provide due to its fast and selective

20 heating.

21 Herein, continuous manufacturing of self-assembled hierarchical ellipsoid hematite 22 superstructures (Hem-SSs) with an average dimension of $\sim 100-200 \mathrm{~nm}$ using a microwave 23 promoted continuous flow approach in an aqueous solution using $\mathrm{Fe}\left(\mathrm{NO}_{3}\right)_{3} \cdot 9 \mathrm{H}_{2} \mathrm{O}$ as the only 24 precursor is presented for the first time. The effect of precursor concentration and flow rate 25 on the geometry and morphology of the formed particles were investigated. The results 
1 obtained by $\mathrm{MH}$ were also compared with the results of particles produced by $\mathrm{CH}$ under

2 similar reaction conditions. Furthermore, the reproducibility of the process was examined.

\section{Experimental}

4 Synthesis of Hematite Nanoparticles. All chemicals were purchased from Sigma-Aldrich

5 and used as received. The microwave promoted continuous flow method consisted of a flow

6 reactor $(6 \mathrm{~mL})$ made of $1 / 8$ " PTFE tubing, a CEM single-mode microwave system, a syringe

7 pump, a temperature probe positioned at the exit of reactor, a sample/waste collection unit

8 with backpressure regulator and an ice-bath. For the synthesis of particles using $\mathrm{CH}$, the

9 microwave instrument was replaced by a thermal bath using glycerol as a heating medium. In

10 a typical procedure, a $50 \mathrm{~mL}$ syringe filled with $0.1 \mathrm{~mol} \mathrm{~L}^{-1}$ of iron (III) nitrate nonahydrate

$11\left(\mathrm{Fe}\left(\mathrm{NO}_{3}\right)_{3} .9 \mathrm{H}_{2} \mathrm{O}, 99.9 \%\right)$ solution (pale yellow in color) dissolved in deionized water at

12 room temperature was connected to the flow reactor and the reactor was filled with the

13 precursor solution. The pressure of the flow reactor was adjusted at 20 psi using a pressurized

14 air cylinder. Pressure adjustment was provided via air controlled by a pressure regulator (20

15 psi) with a gas escape route immersed in a water bath. The precursor was pumped into the

16 flow reactor at a flow rate of $1 \mathrm{~mL} \mathrm{~min}^{-1}$ and pre-adjusted microwave irradiation (40 W) was

17 applied simultaneously. After $8 \mathrm{~min}$, the temperature probe displayed a constant temperature

18 value $\left(\sim 119-120^{\circ} \mathrm{C}\right)$ and $8 \mathrm{~mL}$ of the pumped solution was collected in waste collection unit.

19 Thereafter, the main product mixture passed through an ice-bath to cool down below room

20 temperature and was collected in a sample collection unit. The mixture was centrifuged at

$212500 \mathrm{rpm}$ for $90 \mathrm{~min}$ to recover the particles formed. Recovered particles were washed by

22 deionized water and re-centrifuged, isolated and dried at room temperature for

23 characterization.

24 Materials Characterization.The X-ray diffraction (XRD) patterns of samples were obtained

25 with a Bruker D8 Advance Powder X-ray diffractometer with a Mo-K $\mathrm{K}_{\alpha}(\lambda=0.71 \AA)$ radiation 
1 source. Diffraction patterns were collected from $10^{\circ}$ to $70^{\circ}$ and a step size of $0.002 \% \mathrm{~s}$ was

2 used. Field emission scanning electron microscopy (FESEM) was employed to observe the

3 size and shape of the nanomaterials, using a JEOL JSM-7401F operating at $3-5 \mathrm{kV}$. Materials

4 were tested in powder form prepared from ethanol dispersions. UV/Vis spectra were obtained

5 from stable dispersions of produced particles in ethanol using a Shimadzu UV-2550 UV/Vis

6 spectrophotometer. High-resolution XPS was performed by a Thermo Scientific K-alpha

7 photoelectron spectrometer with monochromatic $\mathrm{Al}-\mathrm{K}_{\alpha}$ radiation; peak positions were

8 referenced to $\mathrm{C} 1 \mathrm{~s}$ line at $284.5 \mathrm{eV}$ and the CasaXPS software was used for data processing.

9 Transmission electron microscopy (TEM) and high resolution transmission electron

10 microscopy (HRTEM) were performed using Jeol JEM-1010 and JEOL-2010F coupled with

11 an EDS detector (Oxford Instruments) instruments, respectively. TEM samples were prepared

12 from stable dispersions of particles prepared in ethanol by dropping on carbon coated copper

13 grids. Particle size distribution was estimated from TEM data measuring particle size using

14 ImageJ. All graphs and statistical analysis were obtained by OriginLab software (Origin9.1).

\section{Results and discussion}

16 Preparation of HEM-SSs. Highly pure and crystalline Hem-SSs, reddish-brown in color,

17 were successfully fabricated via a cheap and readily available precursor, $\mathrm{Fe}\left(\mathrm{NO}_{3}\right)_{3} \cdot 9 \mathrm{H}_{2} \mathrm{O}$,

18 under flow conditions. Unlike previously reported conventional and microwave-assisted

19 hydrothermal batch processes, 6, 8, 9, 16 MWPF synthesis of Hem-SSs does not require any

20 reducing agent (e.g. urea), surfactant or template. The potential by-products have a high

21 solubility in water (e.g. $\mathrm{HNO}_{3}$ ), facilitating the isolation/purification of synthesized ellipsoid

22 Hem-SSs, thus low speed centrifugation was applied. Hem-SSs were produced at $120{ }^{\circ} \mathrm{C}$

23 under $40 \mathrm{~W}$ fixed MW power, $1 \mathrm{~mL} \mathrm{~min}^{-1}$ flow rate and 20 psi applied back pressure. It is

24 also worth noting that the temperature value $\left(120^{\circ} \mathrm{C}\right)$ was recorded outside the $\mathrm{MH}$ zone

25 using a temperature probe positioned $c a .5 \mathrm{~cm}$ away from the reactor exit from the 
1 microwave irradiated zone. Thus, the inside temperature of the flow reactor is likely to be

2 somewhat higher than that of the recorded temperature outside the microwave cavity. The

3 current configuration of the reactor and small microwave cavity make the measurement of the

4 temperature of hot fluid inside the reactor very difficult. In order to make our comparison

5 more accurate, we estimated the temperature at the exit of the microwave irradiated zone,

6 taking into account the heat transfer between the fluid inside the PTFE tubing and the outside

7 surrounding air (See ESI for calculations). The estimated fluid temperatures at the exit of

8 the microwave irradiated zone for different fluid flow rates are listed in Table 1. It can be

9 seen that the temperature difference between the inside temperature near the exit and the 10 measured is quite small, less than $7{ }^{\circ} \mathrm{C}$ at the current conditions.

11 Table 1 Estimated fluid temperature at the exit of the microwave irradiated zone

\begin{tabular}{|c|c|c|}
\hline $\begin{array}{c}\text { Fluid volume flow rate }(\mathrm{F}), \mathrm{mL} \\
\mathrm{min}^{-1}\end{array}$ & Fluid mass flow rate $(\mathrm{m}), \mathrm{g} \mathrm{s}^{-1}$ & $\begin{array}{c}\text { Temperature at the exit of the } \\
\text { microwave irradiated zone } \\
\left(\mathrm{t}_{i, M W}\right),{ }^{\circ} \mathrm{C}\end{array}$ \\
\hline 1 & 0.01663 & 126.7 \\
\hline 2 & 0.03327 & 123.3 \\
\hline 5 & 0.08317 & 121.3 \\
\hline
\end{tabular}

13 The X-ray diffraction (XRD) patterns of iron oxide particles prepared by the MWPF system 14 using different concentrations $\left(0.05,0.1\right.$ and $0.2 \mathrm{~mol} \mathrm{~L}^{-1}$ precursor) show the presence of 15 characteristic hematite $\left(\alpha-\mathrm{Fe}_{2} \mathrm{O}_{3}\right)$ peaks (Figure 1a). In contrast, an inseparable mixture with 16 poor crystallinity, attributed to the mixture of hematite and goethite particles indicated by $17 \mathrm{XRD}$, was obtained when the reaction was conducted by $\mathrm{CH}$ using 0.1 and $0.2 \mathrm{~mol} \mathrm{~L}^{-1}$ $18 \mathrm{Fe}\left(\mathrm{NO}_{3}\right)_{3} \cdot 9 \mathrm{H}_{2} \mathrm{O}$ precursor concentrations at $120{ }^{\circ} \mathrm{C}$ and even $140{ }^{\circ} \mathrm{C}$ (not shown) (Figure

19 1a). When the precursor concentration was decreased to $0.05 \mathrm{~mol} \mathrm{~L}^{-1} \mathrm{Fe}\left(\mathrm{NO}_{3}\right)_{3} \cdot 9 \mathrm{H}_{2} \mathrm{O}$, no 20 particles were isolated when reaction was performed by $\mathrm{CH}$ at $120{ }^{\circ} \mathrm{C}$. On the other hand, 21 highly pure and crystalline hematite particles were obtained (confirmed by sharp and narrow $22 \mathrm{XRD}$ peaks) when $0.05 \mathrm{M} \mathrm{Fe}\left(\mathrm{NO}_{3}\right)_{3} \cdot 9 \mathrm{H}_{2} \mathrm{O}$ precursor was used (Figure 1a). The observed 23 XRD peaks for Hem-SSs (ICSD — 96075) were assigned to Miller's indices of [012], [104], 
1 [110], [113], [202], [024], [116], [018], [214], [300], [208], [1010], [220], [306], [223], [312],

2 [0210], [134], [315] and [2110]. When high concentration of precursor $\left(0.1\right.$ and $0.2 \mathrm{~mol} \mathrm{~L}^{-1}$

$\left.3 \mathrm{Fe}\left(\mathrm{NO}_{3}\right)_{3} \cdot 9 \mathrm{H}_{2} \mathrm{O}\right)$ was used, Hem-SSs were again produced successfully. However, slightly

4 broadened XRD peaks were observed, suggestive of less crystalline hematite particle

5 formation possibly due to insufficient microwave energy provided. XRD results reveal that

6 the degree of crystallinity of the MWPF system synthesized Hem-SSs was related to the

7 precursor concentration. Low precursor concentrations yielded highly crystalline hematite

8 preparation.

9 The oxidation state of $\mathrm{Fe}$ in Hem-SSs prepared by MWPF using $0.05 \mathrm{~mol} \mathrm{~L}^{-1} \mathrm{Fe}\left(\mathrm{NO}_{3}\right)_{3} .9 \mathrm{H}_{2} \mathrm{O}$

10 precursor was further analyzed by XPS. Previous studies for $\alpha-\mathrm{Fe}_{2} \mathrm{O}_{3}$ reported two main

11 peaks positioned at $c a$. 724 and $711 \mathrm{eV}$, attributed to $\mathrm{Fe} 2 \mathrm{p}_{1 / 2}$ and $\mathrm{Fe} 2 \mathrm{p}_{3 / 2}$, respectively. ${ }^{22}$ It

12 was also shown that the latter one was narrower and stronger ${ }^{23}$ and these peaks were clearly

13 accompanied by satellite structures on their high binding-energy side, at about $8 \mathrm{eV}^{22}$

14 Consistent with previous literature, XPS analysis of Hem-SSs displayed four peaks at $c a$.

$15733,724,719$ and $711 \mathrm{eV}$, confirming the synthesis of pure hematite structures (Figure 1b). 

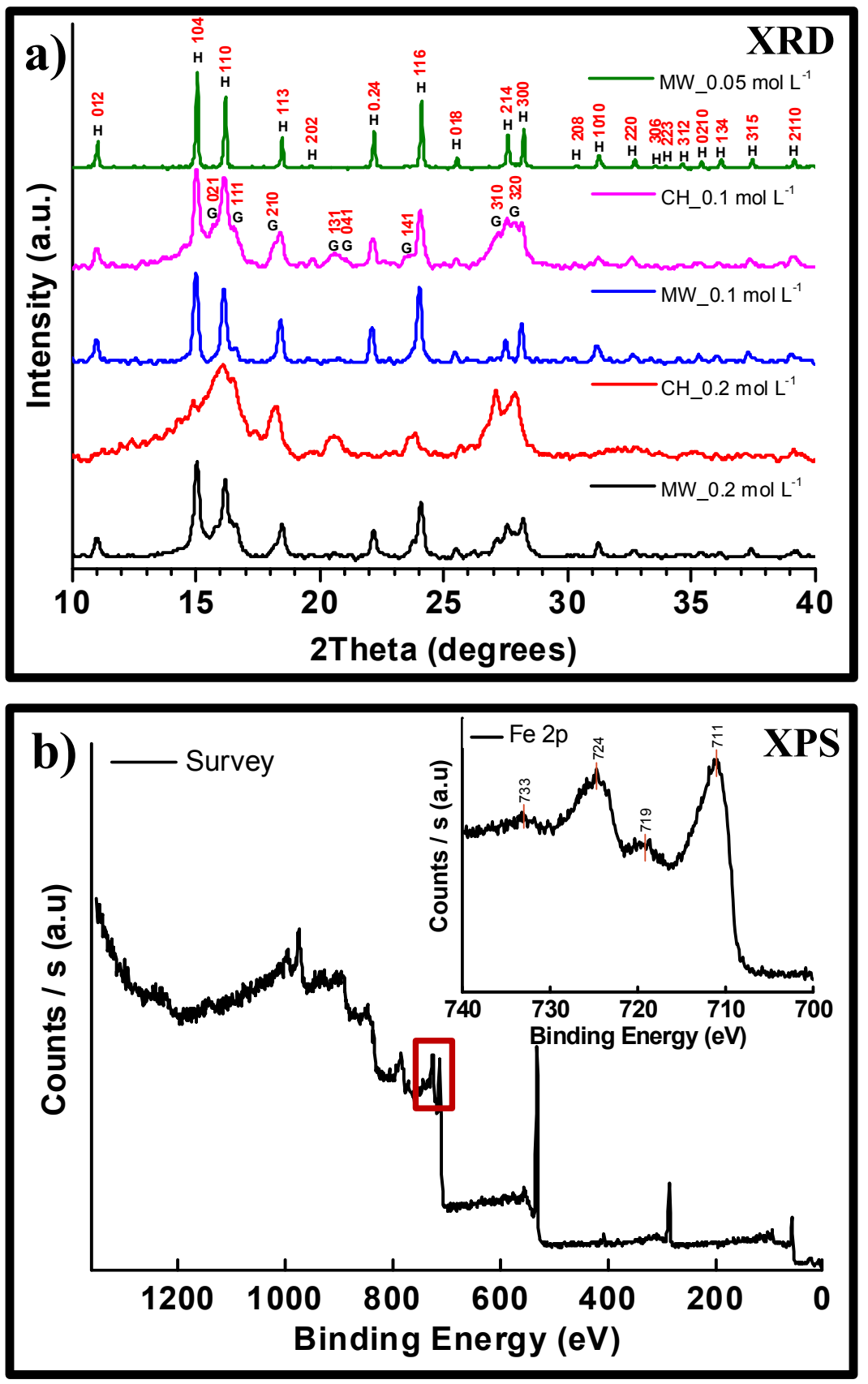

2 Figure 1 (a) XRD patterns of $\mathrm{MH}$ and $\mathrm{CH}$ assisted flow system synthesized particles at

$3120{ }^{\circ} \mathrm{C}$ using $0.05,0.1$ and $0.2 \mathrm{~mol} \mathrm{~L}^{-1} \mathrm{Fe}\left(\mathrm{NO}_{3}\right)_{3} .9 \mathrm{H}_{2} \mathrm{O}$ precursor. Molybdenum K-alpha

$4 \quad(\lambda=0.71 \AA)$ was used as a source. 'G' corresponds to goethite. (b) XPS spectrum of MWPF

5 synthesized Hem-SSs at $1 \mathrm{~mL} \mathrm{m^{-1 }}$ flow rate (Reactor volume: $6 \mathrm{~mL}$ ) using $0.05 \mathrm{~mol} \mathrm{~L}^{-1}$

$6 \mathrm{Fe}\left(\mathrm{NO}_{3}\right)_{3} .9 \mathrm{H}_{2} \mathrm{O}$ precursor. Inset: Expanded Fe 2p XPS spectrum of Hem-SSs. 
1 Absorption spectroscopy has been widely used to characterize hematite particles in solution

2 and solid state. ${ }^{23,24}$ As expected, UV-vis spectra of isolated Hem-SSs show an absorption

3 band at $c a .390 \mathrm{~nm}$ and a weak shoulder at $c a .530 \mathrm{~nm}$, characteristic of pure hematite,

4 compared to $\mathrm{Fe}\left(\mathrm{NO}_{3}\right)_{3} \cdot 9 \mathrm{H}_{2} \mathrm{O}$ precursor (Figure 2).

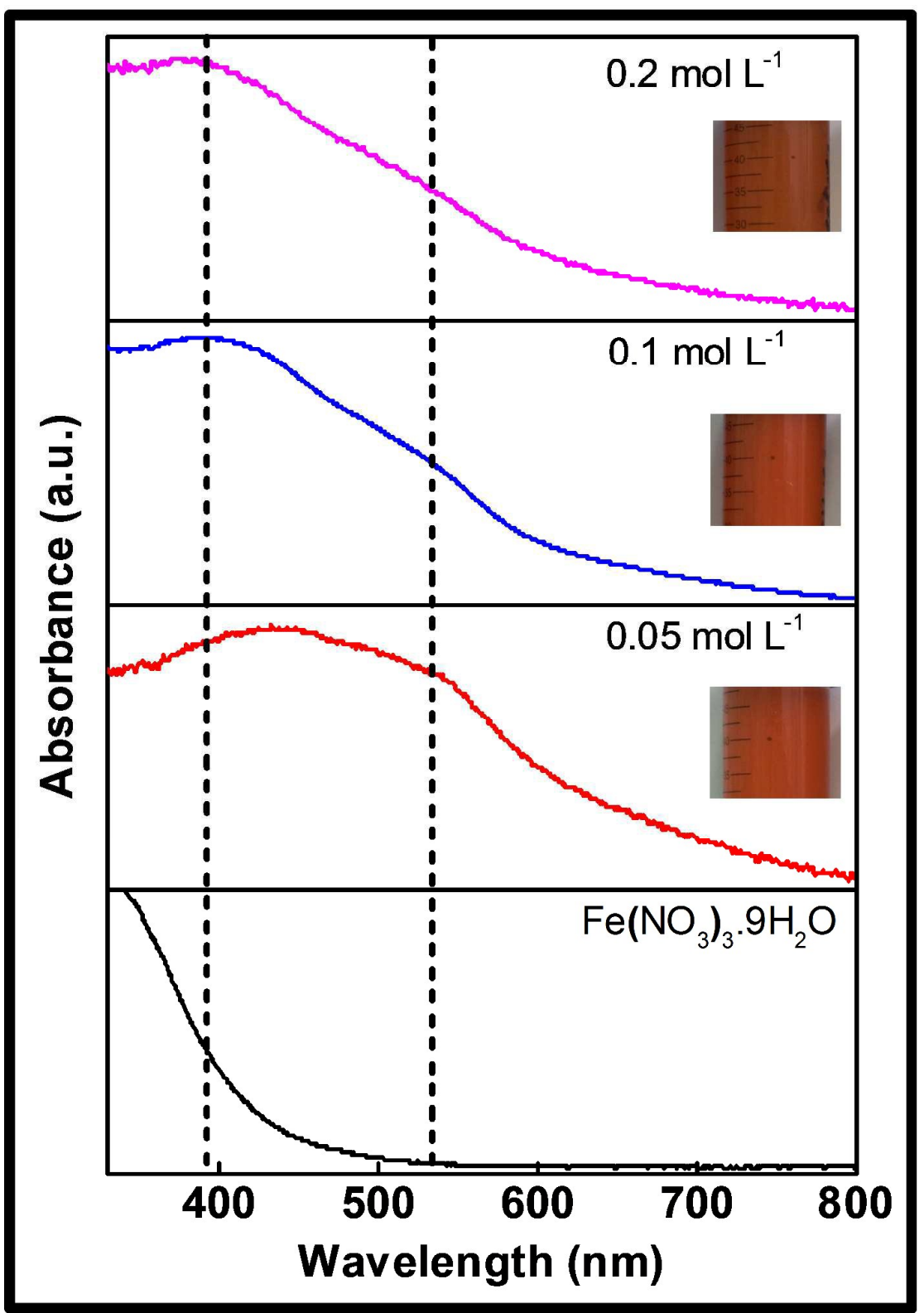

6 Figure 2 Photos and absorption spectra of MWPF system synthesized Hem-SSs using 0.05,

$7 \quad 0.1$ and $0.2 \mathrm{~mol} \mathrm{~L}-1 \mathrm{Fe}\left(\mathrm{NO}_{3}\right)_{3} \cdot 9 \mathrm{H}_{2} \mathrm{O}$ precursor, and pure $\mathrm{Fe}\left(\mathrm{NO}_{3}\right)_{3} .9 \mathrm{H}_{2} \mathrm{O}$ precursor. 
1 Furthermore, it was noticed that the characteristic absorption bands of Hem-SSs prepared by

$20.05 \mathrm{~mol} \mathrm{~L}^{-1} \mathrm{Fe}\left(\mathrm{NO}_{3}\right)_{3} .9 \mathrm{H}_{2} \mathrm{O}$ precursor were red-shifted by $\sim 20 \mathrm{~nm}$ compared to 0.1 and 0.2

$3 \mathrm{~mol} \mathrm{~L}^{-1}$ precursor concentration. Although this type of shift is generally attributed to larger

4 particle size, it may also be due to high crystallinity of the produced particles using 0.05 mol

$5 \mathrm{~L}^{-1}$ precursor, coinciding with XRD patterns of these samples. ${ }^{25}$ Conversely, no clear

6 hematite related absorption band was observed for the isolated particles produced by $\mathrm{CH}$ at

$7 \quad 120{ }^{\circ} \mathrm{C}$ using $0.1 \mathrm{~mol} \mathrm{~L}^{-1} \mathrm{Fe}\left(\mathrm{NO}_{3}\right)_{3} .9 \mathrm{H}_{2} \mathrm{O}$ precursor in a flow reactor although XRD pattern

8 (please see Figure 1a) of isolated particles revealed a mixture of goethite and hematite

9 particles (ESI Figure S1). On the other hand, consistent with observed XRD peaks, the

10 isolated particles produced by $\mathrm{CH}$ at $120{ }^{\circ} \mathrm{C}$ using $0.2 \mathrm{~mol} \mathrm{~L}^{-1} \mathrm{Fe}\left(\mathrm{NO}_{3}\right)_{3} \cdot 9 \mathrm{H}_{2} \mathrm{O}$ precursor

11 showed an absorption band at $c a .400 \mathrm{~nm}$, probably due to the presence of relatively high

12 concentration of hematite particles in isolated mixture, compared to $0.1 \mathrm{~mol} \mathrm{\textrm {L } ^ { - 1 }}$

$13 \mathrm{Fe}\left(\mathrm{NO}_{3}\right)_{3} .9 \mathrm{H}_{2} \mathrm{O}$ precursor. Assuming that the temperature of the reactor in the microwave

14 cavity was somewhat higher than $120^{\circ} \mathrm{C}$ as predicted by our calculations, the reaction was

15 further performed by $\mathrm{CH}$ at $140{ }^{\circ} \mathrm{C}$ using $0.1 \mathrm{~mol} \mathrm{~L}^{-1} \mathrm{Fe}\left(\mathrm{NO}_{3}\right)_{3} \cdot 9 \mathrm{H}_{2} \mathrm{O}$ precursor. However, no

16 characteristic hematite related UV-vis absorption bands at $c a .390$ and $530 \mathrm{~nm}$ were obtained,

17 suggesting that pure hematite particles could not be prepared by $\mathrm{CH}$ at 120 and $140{ }^{\circ} \mathrm{C}$ under

18 similar experimental conditions (ESI Figure S1). All these are consistent with results

19 obtained by XRD measurements.

20 Transmission electron microscopy (TEM) provided insight into the morphology, particle size

21 distribution and sub-units of Hem-SSs. TEM images of hematite particles prepared using

$220.05,0.1$ and $0.2 \mathrm{~mol} \mathrm{~L}^{-1} \mathrm{Fe}\left(\mathrm{NO}_{3}\right)_{3} .9 \mathrm{H}_{2} \mathrm{O}$ show ellipsoid hematite structures with particle size

23 (length/width) distribution of $180 \pm 92 \mathrm{~nm} / 140 \pm 67 \mathrm{~nm}, 124 \pm 62 \mathrm{~nm} / 75 \pm 33 \mathrm{~nm}$ and $112 \pm 69$

$24 \mathrm{~nm} / 73 \pm 34 \mathrm{~nm}$, respectively (Figure 3a-f). Close inspection of TEM image of ellipsoid

25 hematite particles reveals that each particle has relatively rough surfaces and is composed of 
1 highly oriented or self-assembled primary hematite particles, with boundaries between them

2 (Figure 3g). The presence of clear particle-particle boundaries suggest that subunits of Hem-

3 SSs are not fused and they might be dispersed by applying external forces (e.g. sonication,

4 mechanical stirring etc.).

5
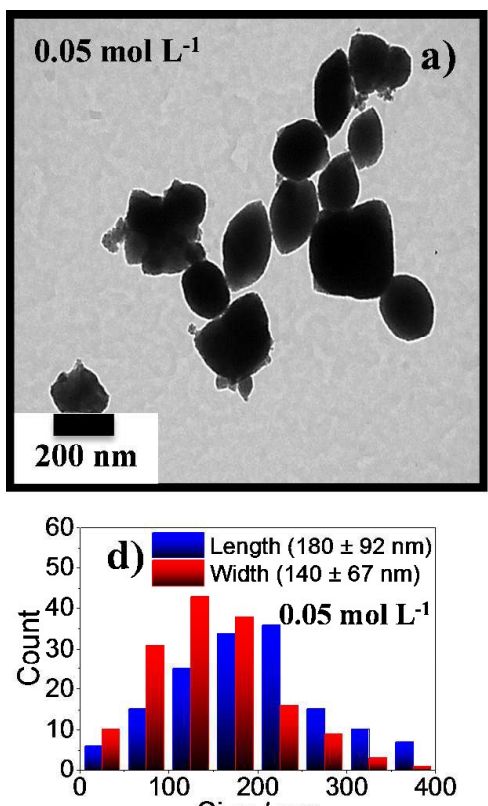

$\mathrm{Size} / \mathrm{nm}$

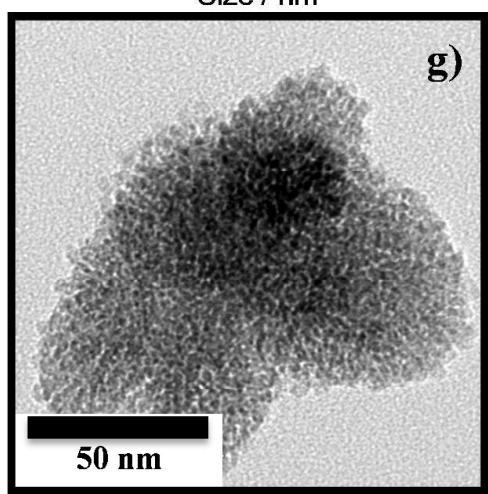

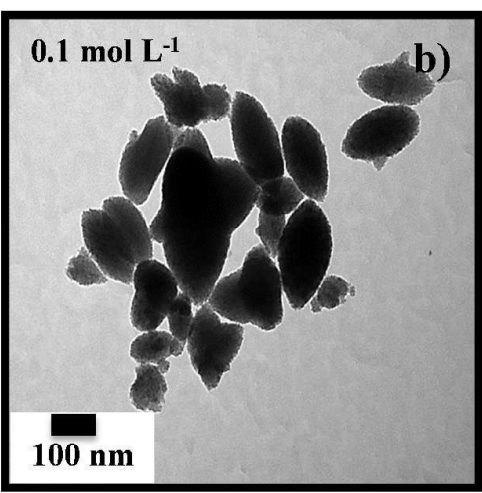
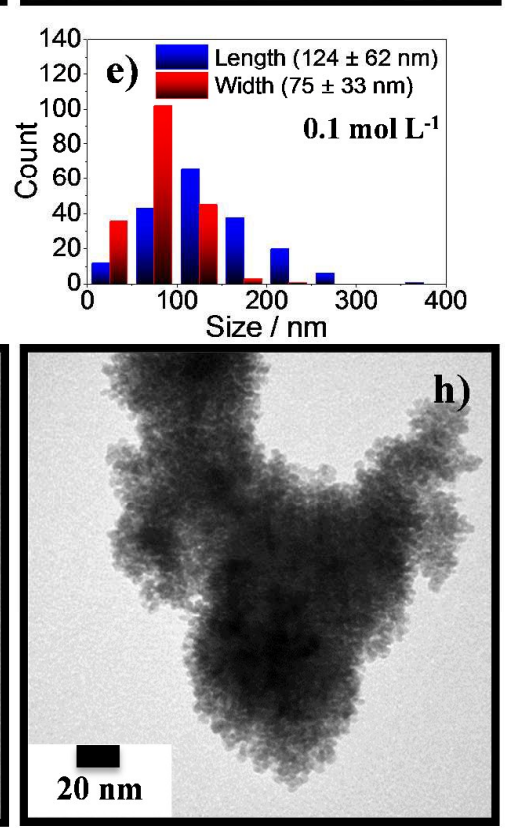
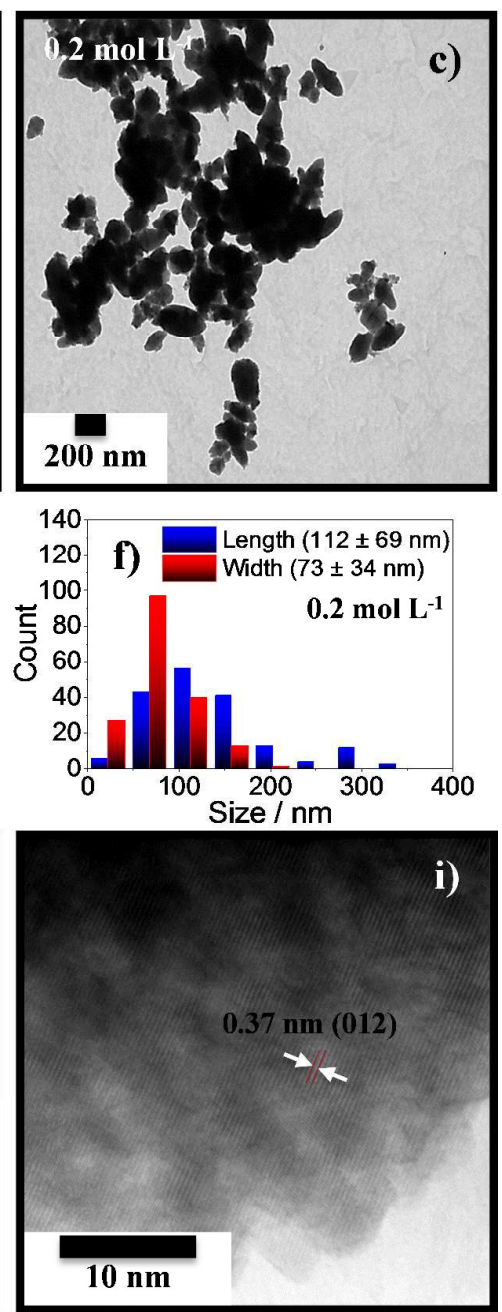

7 Figure 3 TEM images of MWPF system synthesized ellipsoid Hem-SSs using 0.05, 0.1 and

$80.2 \mathrm{~mol} \mathrm{~L}-1 \mathrm{Fe}\left(\mathrm{NO}_{3}\right)_{3} .9 \mathrm{H}_{2} \mathrm{O}$ precursor and (a-c) particle size distribution (length/width) of 9 ellipsoid Hem-SSs (d-f). TEM images of MWPF synthesized ellipsoid Hem-SSs before (g)

10 and after (h) mild sonication using $0.05 \mathrm{~mol} \mathrm{~L}^{-1} \mathrm{Fe}\left(\mathrm{NO}_{3}\right)_{3} \cdot 9 \mathrm{H}_{2} \mathrm{O}$ precursor. HRTEM image of

11 ellipsoid Hem-SSs using $0.05 \mathrm{~mol} \mathrm{~L}^{-1} \mathrm{Fe}\left(\mathrm{NO}_{3}\right)_{3} \cdot 9 \mathrm{H}_{2} \mathrm{O}$ precursor (i). 
1 Thus, mild sonication (750 W sonic probe, 40\% amplitude) was applied to ellipsoid Hem-SSs

2 in ice cooled ethanol for 5 min. High-resolution TEM (HR-TEM) images of mildly sonicated

3 Hem-SSs show partial exfoliation of uniform granular primary hematite nanocrystals

4 approximately 5-10 $\mathrm{nm}$ in size (Figure 3h), suggesting that interaction between the subunits

5 is relatively strong. Furthermore, it is worth noting that the ellipsoid morphologies of Hem-

6 SSs are preserved, suggestive of highly-ordered stable superstructure. The lattice fringes in a

7 typical HRTEM image (Figure 3i) are separated by $\sim 3.7 \AA$, which agrees well with the [012]

8 lattice spacing of hematite and further confirm that $\alpha-\mathrm{Fe}_{2} \mathrm{O}_{3} \mathrm{NPs}$ (e.g. crystallinity) are not

9 altered via mild sonication. It is also worth noting that HRTEM analysis of $\alpha-\mathrm{Fe}_{2} \mathrm{O}_{3}$

10 mesocrystals prepared by conventional heating in previous literature using both

$11 \mathrm{Fe}\left(\mathrm{NO}_{3}\right)_{3} \cdot 9 \mathrm{H}_{2} \mathrm{O}^{6}$ and $\mathrm{FeCl}_{3} \cdot 6 \mathrm{H}_{2} \mathrm{O}^{9}$ exhibited lattice fringes separated by $\sim 2.5 \AA$, attributed to

12 [110] facet as compared to Hem-SSs with [012] facet prepared by MWPF system. This

13 probably suggests that microwave heating induces crystal growth along the [012] direction. It

14 is therefore believed that mesocrystals prepared by MWPF system may show unusual

15 activities due to their different crystal facet and lattice spacing that may provide more

16 accessible surface compared to conventionally prepared mesocrystals. ${ }^{6,9}$ On the other hand,

17 no ellipsoid pure hematite was observed by TEM analysis of particles prepared by CH (ESI

18 Figure S2). HRTEM image of samples showed $\sim 10 \mathrm{~nm}$ particles with irregular shapes and

19 lattice spacing of $\sim 2.0,2.4$ and $2.7 \AA$, corresponding to [131] lattice spacing of goethite, and

20 [104] and [110] lattice spacing of hematite, respectively, further confirming that $\mathrm{CH}$ mainly

21 produced a mixture of hematite and goethite nanoparticles. Overall (HR)TEM analysis of

22 Hem-SSs suggests that MWPF system is able to produce highly stable and ordered Hem-SSs.

23 Effect of Reactant Flow Rate on Synthesis of Hem-SSs. The effect of reactant flow rate on

24 the physical properties of the particles was studied by TEM, UV-vis and Raman

25 spectroscopy. Typical reaction conditions $\left(120{ }^{\circ} \mathrm{C}, 0.1 \mathrm{~mol} \mathrm{~L}^{-1}, 6 \mathrm{~mL}\right.$ reactor $)$ and applied 
1 back pressure (20 psi) were kept constant and the reaction was carried out at flow rates of 1,2

2 and $5 \mathrm{~mL} \mathrm{~min}{ }^{-1}$, where $1 \mathrm{~mL} \min ^{-1}$ was the minimum reliable flow rate in the current

3 configuration. No visible particle formation was observed at 2 and $5 \mathrm{~mL} \mathrm{~min}^{-1}$ flow rates.

4 Thus, the isolated hematite particles for $1 \mathrm{~mL} \mathrm{~min}^{-1}$ flow rate and soluble crude mixtures for 2

5 and $5 \mathrm{~mL} \mathrm{~min}^{-1}$ flow rates were used for bulk UV-vis and Raman analysis. UV-vis spectrum

6 of the isolated particles synthesized at $1 \mathrm{~mL}$ min-1 flow rate showed the characteristic

7 hematite absorption bands while

8

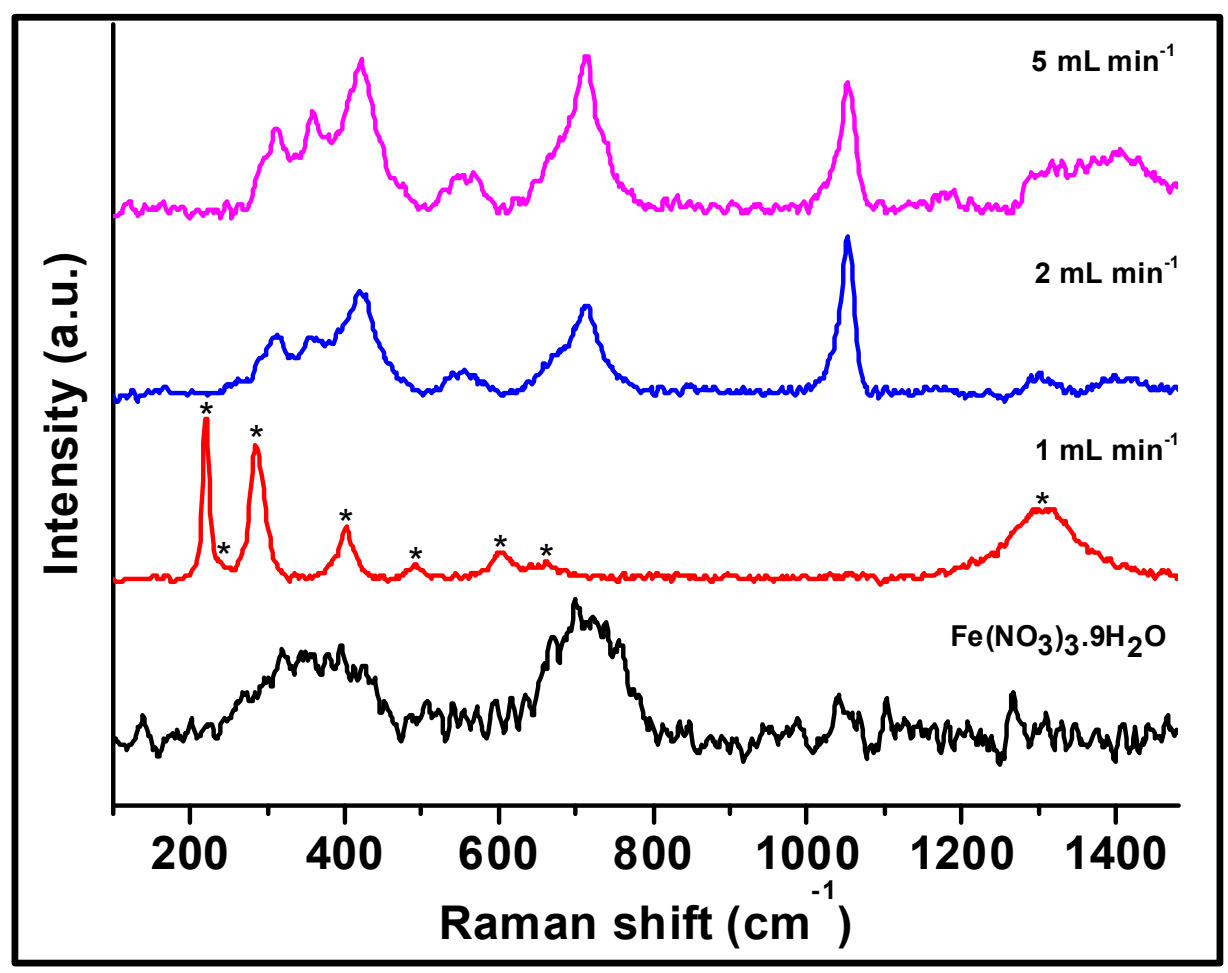

9 Figure 4 Raman spectra of MWPF system synthesized ellipsoid Hem-SSs using 0.05 mol L ${ }^{-1}$

$10 \mathrm{Fe}\left(\mathrm{NO}_{3}\right)_{3} \cdot 9 \mathrm{H}_{2} \mathrm{O}$ precursor at 1,2 and $5 \mathrm{~mL} \mathrm{~min}^{-1}$ flow rate, and pure $\mathrm{Fe}\left(\mathrm{NO}_{3}\right)_{3} \cdot 9 \mathrm{H}_{2} \mathrm{O}$

11 precursor for comparison. * corresponds to the characteristic hematite related Raman shifts.

12 the crude mixtures prepared at higher flow rates showed no clear bands (ESI Figure S3). In

13 agreement with previous literature, ${ }^{26,27}$ Raman spectra of Hem-SSs prepared via $1 \mathrm{~mL} \mathrm{~min}{ }^{-1}$

14 flow rate displayed characteristic hematite $\left(\alpha-\mathrm{Fe}_{2} \mathrm{O}_{3}\right)$ Raman shifts at ca. 201, 240, 285, 401, 
$1492,601,665$ and $1300 \mathrm{~cm}^{-1}$, compared to precursor signals positioned at 356 and $712 \mathrm{~cm}^{-1}$

2 (Figure 4). In contrast, reaction mixtures obtained at 2 and $5 \mathrm{~mL} \mathrm{~min}{ }^{-1}$ flow rates showed no

3 hematite related Raman shifts, suggesting that low residence times ( $3 \mathrm{~min}$ for $2 \mathrm{~mL} \mathrm{~min}{ }^{-1}$ and

$41.2 \mathrm{~min}$ for $5 \mathrm{~mL} \mathrm{~min}^{-1}$ ) were not enough to produce hematite particles (Figure 4). Further

5 TEM analysis of crude reaction product $\left(2 \mathrm{~mL} \mathrm{~min}^{-1}\right.$ flow rate $)$ showed a mixture of small

6 particles $1-2 \mathrm{~nm}$ in size, some ellipsoid ( $\sim 200 \mathrm{~nm}$ in length) and spherical $(\sim 100 \mathrm{~nm}$ or less)

7 particles, suggesting that the minimum residence time required to prepare pure ellipsoid

8 Hem-SSs should probably be at $c a .6 \min \left(1 \mathrm{~mL} \mathrm{~min}^{-1}\right)$ under the experimental conditions

9 utilized (ESI Figure S4). Furthermore, no ellipsoid particle formation was observed at $5 \mathrm{~mL}$

$10 \min ^{-1}$ flow rate although some non-hematite spherical particles, confirmed by Raman

11 analysis, $(\sim 20-30 \mathrm{~nm}$ and $\sim 1-2 \mathrm{~nm}$ in size $)$ were observed.

12 Reproducibility of Synthesis. Reproducibility of the MWPF process was tested by repeating

13 the fabrication of Hem-SSs two more times under the same experimental conditions using 0.1

$14 \mathrm{~mol} \mathrm{~L}^{-1} \mathrm{Fe}\left(\mathrm{NO}_{3}\right)_{3} \cdot 9 \mathrm{H}_{2} \mathrm{O}$ precursor at $1 \mathrm{~mL} \mathrm{~min}^{-1}$ flow rate. Isolated Hem-SSs were

15 characterized by TEM. In all cases TEM analyses showed ellipsoid Hem-SSs with particle

16 size distribution of $\sim 130 \mathrm{~nm}$ (length) and $80 \mathrm{~nm}$ (width), confirming that the developed

17 synthesis method is reproducible and capable of producing Hem-SSs with similar size

18 distributions (Figure 5). 

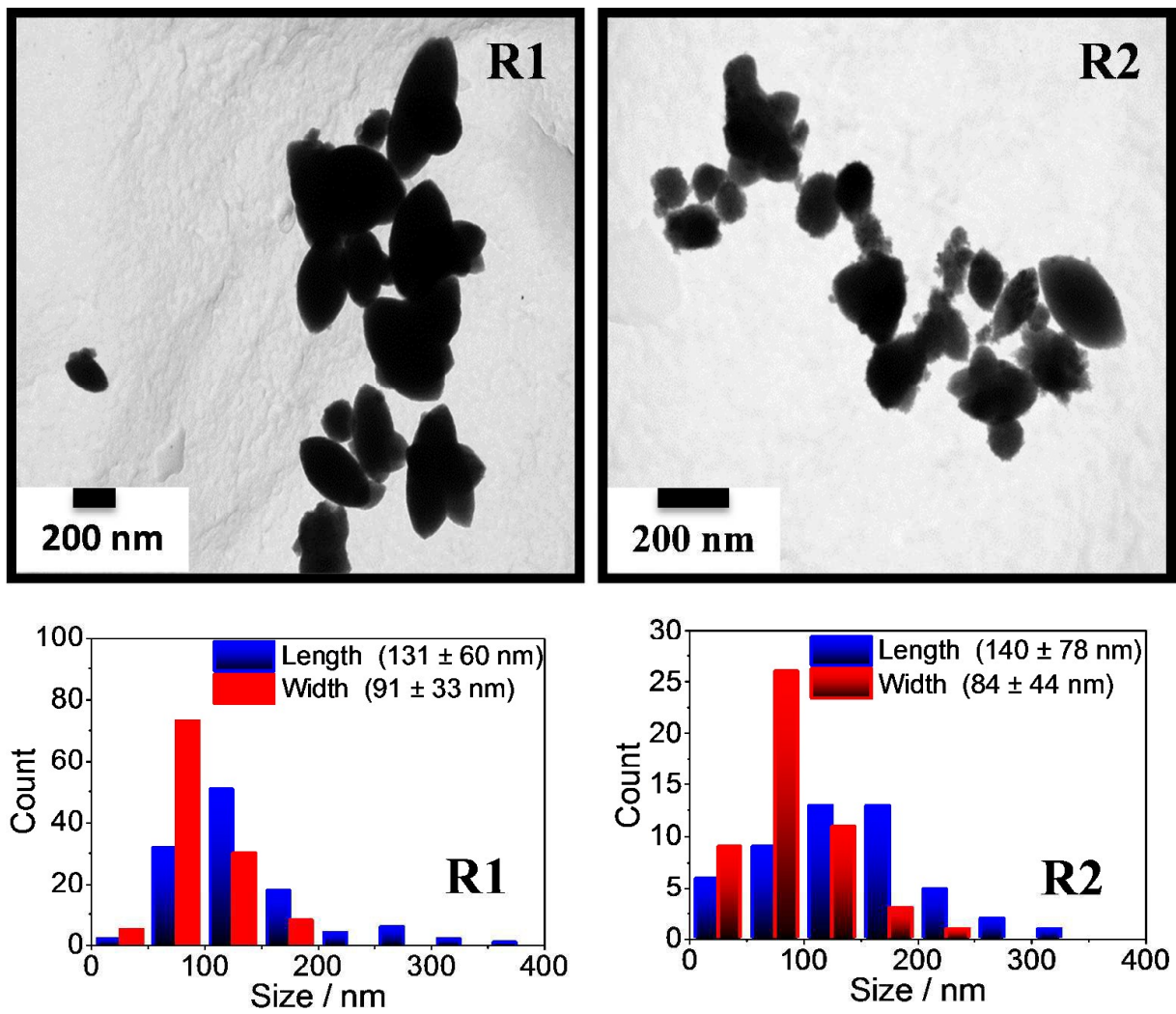

2 Figure 5 TEM images of ellipsoid Hem-SSs produced by two different repeat experiments

3 (R1 and R2) under the same experimental conditions and the particle size distribution of the 4 produced Hem-SSs.

5 Mechanism of Hem-SSs Formation. In agreement with previous literature, ${ }^{8}$ the morphology

6 of hematite particles is thought to be an oriented growth with primary nanoparticles. In

7 general, mesocrystal formation mechanisms are described by the hierarchical self-assembly

8 of primary nanoparticles following a non-classical crystallization route that is based on either

9 self-assembly or ligand-directed assembly of well-aligned small nanoparticles. ${ }^{1-4}$ During the

10 formation of well-oriented superstructures, an equilibrium state is however essential between

11 the interparticle interactions including the dipole-dipole attraction, van der Waals interaction

12 and the double layer repulsion for directed self-assembly of colloidal particles. ${ }^{28,}{ }^{29}$ This type

13 of balance can be facilitated by an external electric or magnetic field if sufficient dipole-

14 dipole interactions are induced. ${ }^{28,}{ }^{29}$ In addition, self-assembly of nanostructures was also 
1 shown in fluidic reactors that provide small reaction volumes and laminar flow,

2 facilitating the fine-adjustment of mixing rates, shear forces and reagent

3 concentrations. 30,31

4 Regarding the formation of ellipsoid Hem-SSs, the multiple effects induced by shear force

5 due to fluid flow and continuously exerted microwave irradiation might have played the key

6 roles, since no other templates/surfactants/organic solvents are present in our reaction system.

7 The shear induced aggregation of nanoparticles can be described by the dimensionless

8 Péclet number; shear forces have a stronger influence on aggregation for high flow Péclet

9 numbers $\left(\mathrm{P}_{\mathrm{e}} \geq 1\right){ }^{30}$ The flow Péclet number for the dilute solutions of $\alpha-\mathrm{Fe}_{2} \mathrm{O}_{3} \mathrm{NPs}$ using

10 particle size of $\sim 10 \mathrm{~nm}$ (estimated by TEM) is $2.74 \times 10^{-6}$, suggesting that self-assembly of

11 hematite primary particles was not probably due to shear induced aggregation. ${ }^{30,32}$ (see ESI

\section{2 for calculations)}

13 Considering that no clear ellipsoid structures (see ESI Figure S2 for TEM images) formed

14 when the conventional heating flow reactor was used, the self-assembly of primary hematite

15 nanocrystals to form stable ellipsoid Hem-SSs is regarded to be induced by microwave

16 irradiation (Figure 6a-b). The surprising effect of microwave heating on the oriented

17 attachment of pre-synthesized $\alpha-\mathrm{Fe}_{2} \mathrm{O}_{3}$ nanoparticles to form large and crystalline ellipsoidal

$18 \alpha-\mathrm{Fe}_{2} \mathrm{O}_{3}$ nanocrystals was also reported when in a batch reactor. ${ }^{33} \alpha-\mathrm{Fe}_{2} \mathrm{O}_{3}$ nanoparticles are

19 known to have magnetic moment that creates dipole-dipole attractions and they can act as

20 antennas and absorb the microwave irradiation selectively. ${ }^{34,}{ }^{35}$ In an electromagnetic field

21 generated by microwave irradiation, $\alpha-\mathrm{Fe}_{2} \mathrm{O}_{3}$ nanoparticles are highly polarized and localized

22 currents are probably created on the "hot surfaces" of $\alpha-\mathrm{Fe}_{2} \mathrm{O}_{3}$ nanoparticles. ${ }^{35}$

23 In order to further understand the effect of microwave irradiation to ellipsoid Hem-SSs

24 formation, control experiments were performed using a microwave batch reactor. In a typical

25 control experiment, $3 \mathrm{~mL}$ of aqueous precursor solution $\left(0.05,0.1\right.$ and $0.2 \mathrm{~mol} \mathrm{~L}^{-1}$ 
$\left.1 \mathrm{Fe}\left(\mathrm{NO}_{3}\right)_{3} \cdot 9 \mathrm{H}_{2} \mathrm{O}\right)$ was irradiated by microwave for $6 \mathrm{~min}$ at $120{ }^{\circ} \mathrm{C}$ without stirring. At low

2 concentration $\left(0.05 \mathrm{~mol} \mathrm{~L}^{-1} \mathrm{Fe}\left(\mathrm{NO}_{3}\right)_{3} \cdot 9 \mathrm{H}_{2} \mathrm{O}\right)$, particles could not be isolated. Hematites,

3 characterised by UV-vis spectroscopy, were produced successfully when high concentration

4 of precursor $\left(0.1\right.$ and $\left.0.2 \mathrm{~mol} \mathrm{~L}^{-1}\right)$ was used (ESI Figure S5a). Produced particles were

5 isolated and further analysed by TEM. In contrast to ellipsoid Hem-SSs synthesized by

6 MWPF system, few ellipsoid particles with irregular morphologies were produced by

7 microwave batch reactor without stirring. (ESI Figure S5b-f), which is partially in

8 agreement with the literature that reported ellipsoid $\alpha-\mathrm{Fe}_{2} \mathrm{O}_{3}$ formation could take place under

9 microwave heating in batch reactor. ${ }^{33}$ It is also worth noting that ellipsoids were obviously

10 formed at high precursor concentration in this study, indicating microwave irradiation can

11 produce ellipsoid but the yield is relative moderate due to limited penetration depth of

12 microwave in a batch reactor.

13 A microwave induced nucleation-aggregation mechanism followed by an oriented attachment

14 of primary $\alpha-\mathrm{Fe}_{2} \mathrm{O}_{3}$ nanoparticles and Oswald ripening may be proposed for the formation of

15 Hem-SSs, although the exact mechanism of the formation at present remains unclear. As

16 shown in Figure 6b, firstly goethite nanocrystals, $\alpha-\mathrm{FeO}(\mathrm{OH})$ are probably generated by the

17 microwave induced forced hydrolysis of $\mathrm{Fe}\left(\mathrm{NO}_{3}\right)_{3} \cdot 9 \mathrm{H}_{2} \mathrm{O} \cdot{ }^{36,} 37$ Due to their high surface

18 energy these freshly formed nanocrystals probably aggregate rapidly in a random manner and

19 subsequently undergo dehydration to form primary $\alpha-\mathrm{Fe}_{2} \mathrm{O}_{3}$ nanoparticles. ${ }^{37}$ Meanwhile,

20 microscopic "hot surfaces" created on particles probably accelerate the crystal growth.

21 Produced primary nanoparticles are subsequently highly polarized under microwave

22 irradiation $(2.45 \mathrm{GHz})$ due to their excellent microwave absorbing characteristic and become

23 energetically more excited. ${ }^{34}$ Highly polarized activated primary $\alpha-\mathrm{Fe}_{2} \mathrm{O}_{3}$ nanoparticles form

24 due to generated dipole-dipole attractions ${ }^{29}$ and start oriented attachment to produce Hem-

25 SSs. ${ }^{38-41}$ In addition, the smooth surface of ellipsoid Hem-SSs observed by TEM is thought 
1 to be due to Oswald ripening after the oriented attachment of primary $\alpha-\mathrm{Fe}_{2} \mathrm{O}_{3}$

2 nanoparticles. ${ }^{36,41}$ The oriented attachment process however leads to formation of ellipsoid

3 Hem-SSs morphologies, which may be related to both the distortion of internal charges in

4 nanoparticle crystal structure to polarize against the external field generated by microwave

5 irradiation and the increased mass of assembled Hem-SSs that affects the particle motion

6 under constant buoyant force of water. The reason behind the stability of hierarchical Hem-

7 SSs formed and the absence of crystallographic fusion to single-crystals is still unknown.

8 However, it could be attributed to both the shape of primary hematite nanoparticles and the

9 residence time of Hem-SSs in the reactor and needs further investigation. 


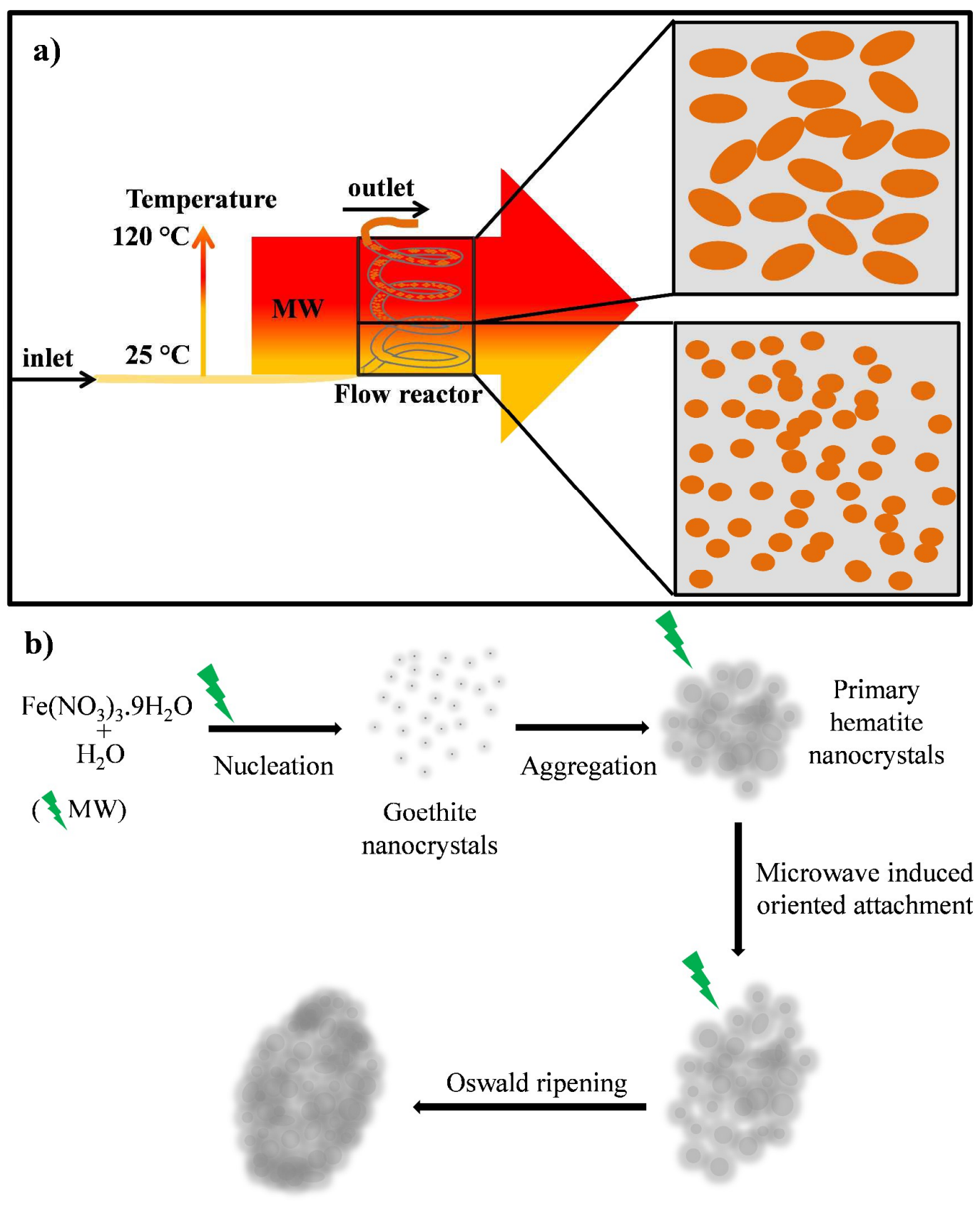

2 Figure 6 Schematic representation of proposed mechanism for microwave assisted directed

3 self-assembly of primary hematite nanoparticles to form Hem-SSs. (a) Fabrication of primary

4 hematite nanocrystals while travelling in the flow reactor (bottom square). Directed self-

5 assembly of primary hematite nanoparticles under continuous microwave irradiation (top

6 square). Colour change on the arrow (yellow to red) shows the possible temperature change

7 throughout the flow reactor. (b) Proposed mechanism scheme for the formation of Hem-SSs. 


\section{Conclusions}

2 Pure and crystalline ellipsoid hematite superstructures were fabricated in $\sim 6$ min time without

3 employing surfactants or templates in a MWPF system using $\mathrm{Fe}\left(\mathrm{NO}_{3}\right)_{3} \cdot 9 \mathrm{H}_{2} \mathrm{O}$ as the only

4 precursor. Microwave irradiation is thought to direct the self-assembly of produced hematite

5 subunits via selective heating and polarization of nanoparticles. Concentration and flow rate

6 of the precursor solution were found to be critical for Hem-SS synthesis. Less crystalline

7 hematite formation was observed at high precursor concentrations $\left(0.1\right.$ and $\left.0.2 \mathrm{~mol} \mathrm{~L}^{-1}\right)$. No

8 hematite particle formation was observed at higher flow rates, indicating the significance of

9 the amount of microwave energy absorbed per unit time. Conversely, $\mathrm{CH}$ was not able to

10 produce pure hematite under identical conditions at 120 and even at $140{ }^{\circ} \mathrm{C}$. The developed

11 sustainable process that benefits from both $\mathrm{MH}$ and flow technology is reproducible and has

12 the potential to fabricate other metal/metal oxide nanoparticles or their self-assembled

13 superstructures, core/shell structures and hybrid nanomaterials.

14 Acknowledgements

15 We gratefully acknowledge the Leverhulme Trust (RPG-2012-582) for research funding.

16

\section{References}

18 1. R.-Q. Song and H. Cölfen, Advanced Materials, 2010, 22, 1301-1330.

19 2. H. Cölfen and M. Antonietti, Angew. Chem. Int. Ed., 2005, 44, 5576-5591.

20 3. L. Bergström, E. V. Sturm, G. Salazar-Alvarez and H. Cölfen, Accounts of Chemical

$21 \quad$ Research, 2015, 48, 1391-1402.

22 4. M.-G. Ma and H. Cölfen, Current Opinion in Colloid \& Interface Science, 2014, 19, 23 56-65.

24 5. T. Tachikawa and T. Majima, NPG Asia Mater, 2014, 6, e100.

25 6. X. Duan, L. Mei, J. Ma, Q. Li, T. Wang and W. Zheng, Chemical Communications, 26 2012, 48, 12204-12206.

27 7. Z. An, J. Zhang, S. Pan and F. Yu, The Journal of Physical Chemistry C, 2009, 113, 28 8092-8096.

29 8. X. Fei, W. Li, Z. Shao, S. Seeger, D. Zhao and X. Chen, Journal of the American 30 Chemical Society, 2014, 136, 15781-15786.

319 9. J. Ma, J. Teo, L. Mei, Z. Zhong, Q. Li, T. Wang, X. Duan, J. Lian and W. Zheng, Journal 32 of Materials Chemistry, 2012, 22, 11694-11700.

33 10. X.-L. Fang, C. Chen, M.-S. Jin, Q. Kuang, Z.-X. Xie, S.-Y. Xie, R.-B. Huang and L.-S. 34 Zheng, Journal of Materials Chemistry, 2009, 19, 6154-6160. 
11. F. Jiao, J.-C. Jumas, M. Womes, A. V. Chadwick, A. Harrison and P. G. Bruce, Journal of the American Chemical Society, 2006, 128, 12905-12909.

12. M. Zhu, Y. Wang, D. Meng, X. Qin and G. Diao, Journal of Physical Chemistry C, 2012, 116, 16276-16285.

13. H.-J. Kim, K.-I. Choi, A. Pan, I.-D. Kim, H.-R. Kim, K.-M. Kim, C. W. Na, G. Cao and J.H. Lee, Journal of Materials Chemistry, 2011, 21, 6549-6555.

14. W. T. Dong and C. S. Zhu, Journal of Materials Chemistry, 2002, 12, 1676-1683.

15. P. M. Kouotou, Z.-Y. Tian, H. Vieker and K. Kohse-Hoeinghaus, Surface \& Coatings Technology, 2013, 230, 59-65.

16. G. Qiu, H. Huang, H. Genuino, N. Opembe, L. Stafford, S. Dharmarathna and S. L. Suib, The Journal of Physical Chemistry C, 2011, 115, 19626-19631.

17. A. Abou-Hassan, O. Sandre and V. Cabuil, Angew. Chem. Int. Ed., 2010, 49, 62686286.

18. M. Nishioka, M. Miyakawa, Y. Daino, H. Kataoka, H. Koda, K. Sato and T. M. Suzuki, Industrial \& Engineering Chemistry Research, 2013, 52, 4683-4687.

19. M. Nishioka, M. Miyakawa, H. Kataoka, H. Koda, K. Sato and T. M. Suzuki, Nanoscale, 2011, 3, 2621-2626.

20. S. Horikoshi, H. Abe, K. Torigoe, M. Abe and N. Serpone, Nanoscale, 2010, 2, 14411447.

21. S. Horikoshi, T. Sumi and N. Serpone, Chemical Engineering and Processing: Process Intensification, 2013, 73, 59-66.

22. T. Fujii, F. M. F. de Groot, G. A. Sawatzky, F. C. Voogt, T. Hibma and K. Okada, Physical Review B, 1999, 59, 3195-3202.

23. A. A. Tahir, K. G. U. Wijayantha, S. Saremi-Yarahmadi, M. Mazhar and V. McKee, Chemistry of Materials, 2009, 21, 3763-3772.

24. D. A. Wheeler, G. Wang, Y. Ling, Y. Li and J. Z. Zhang, Energy \& Environmental Science, 2012, 5, 6682-6702.

25. K. Sivula, R. Zboril, F. Le Formal, R. Robert, A. Weidenkaff, J. Tucek, J. Frydrych and M. Grätzel, Journal of the American Chemical Society, 2010, 132, 7436-7444.

26. D. L. A. de Faria, S. Venâncio Silva and M. T. de Oliveira, Journal of Raman Spectroscopy, 1997, 28, 873-878.

27. M. Hanesch, Geophysical Journal International, 2009, 177, 941-948.

28. J.-M. Meijer, D. V. Byelov, L. Rossi, A. Snigirev, I. Snigireva, A. P. Philipse and A. V. Petukhov, Soft Matter, 2013, 9, 10729-10738.

29. M. Grzelczak, J. Vermant, E. M. Furst and L. M. Liz-Marzán, ACS Nano, 2010, 4, 3591-3605.

30. C.-W. Wang, D. Sinton and M. G. Moffitt, Journal of the American Chemical Society, 2011, 133, 18853-18864.

31. X. Zhang, K. D. Harris, N. L. Y. Wu, J. N. Murphy and J. M. Buriak, ACS Nano, 2010, 4, 7021-7029.

32. J. Vermant and M. J. Solomon, Journal of Physics: Condensed Matter, 2005, 17, R187.

33. W.-W. Wang, Y.-J. Zhu and M.-L. Ruan, Journal of Nanoparticle Research, 2007, 9, 419-426.

34. T. Druzhinina, W. Weltjens, S. Hoeppener and U. S. Schubert, Advanced Functional Materials, 2009, 19, 1287-1292.

35. X. Hu, J. C. Yu, J. Gong, Q. Li and G. Li, Advanced Materials, 2007, 19, 2324-2329.

36. U. Schwertmann, J. Friedl and H. Stanjek, Journal of Colloid and Interface Science, 1999, 209, 215-223. 
1 37. J. F. Banfield, S. A. Welch, H. Zhang, T. T. Ebert and R. L. Penn, Science, 2000, 289, 2 751-754.

3

4

38. M. Ocaña, M. P. Morales and C. J. Serna, Journal of Colloid and Interface Science, 1995, 171, 85-91.

39. A. P. Alivisatos, Science, 2000, 289, 736-737.

40. M. Adachi, Y. Murata, J. Takao, J. Jiu, M. Sakamoto and F. Wang, Journal of the American Chemical Society, 2004, 126, 14943-14949.

7

8

9

41. Y. Cheng, Y. Wang, D. Chen and F. Bao, The Journal of Physical Chemistry B, 2005, 109, 794-798. 